\title{
Notes on the vocalizations of Fire-breasted Flowerpecker (Dicaeum ignipectus)
}

Peter Boesman

In the following we briefly analyze and compare voice of the different races of Fire-breasted Flowerpecker (Dicaeum ignipectus). We also try to quantify the extent of any vocal differences using the criteria proposed by Tobias et al. (2010), as a support for taxonomic review. We have made use of sound recordings available on-line from Xeno Canto (XC) and Macaulay Library (ML).

An overview of voice per race, illustrated with sonograms:

ignipectus: apparently 2 song types: a series of short high-pitched notes rising in pitch, and a series of 2 alternating notes.

India
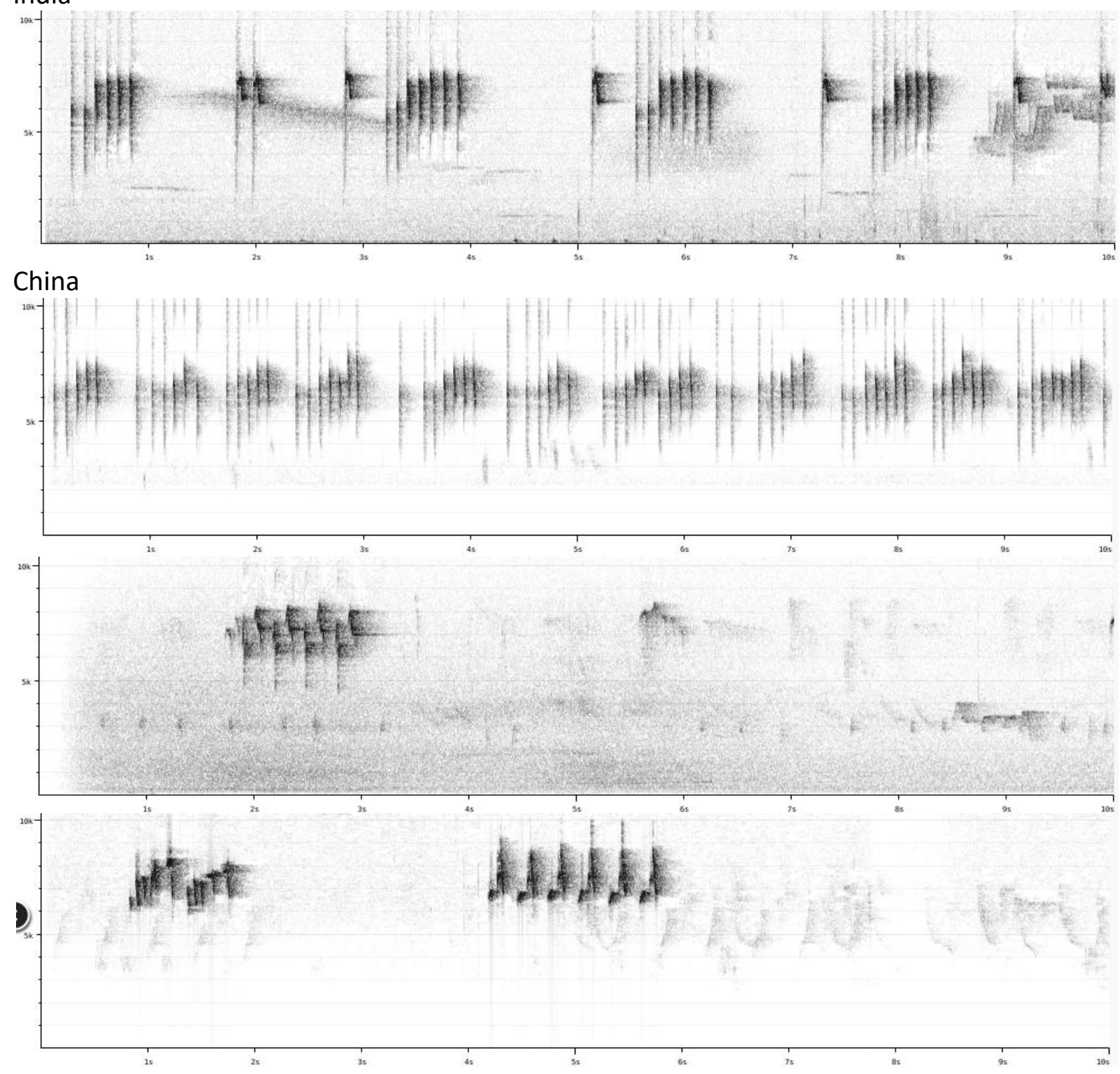


\section{HANDBOOK OF THE \\ BIRDS PF,THE WORLD \\ Aluve}

\section{ORNITHOLOGICAL NOTES}

formosum (Taiwan): apparently 2 song types: a few short high-pitched notes rising in pitch, and a series of 2 alternating notes.

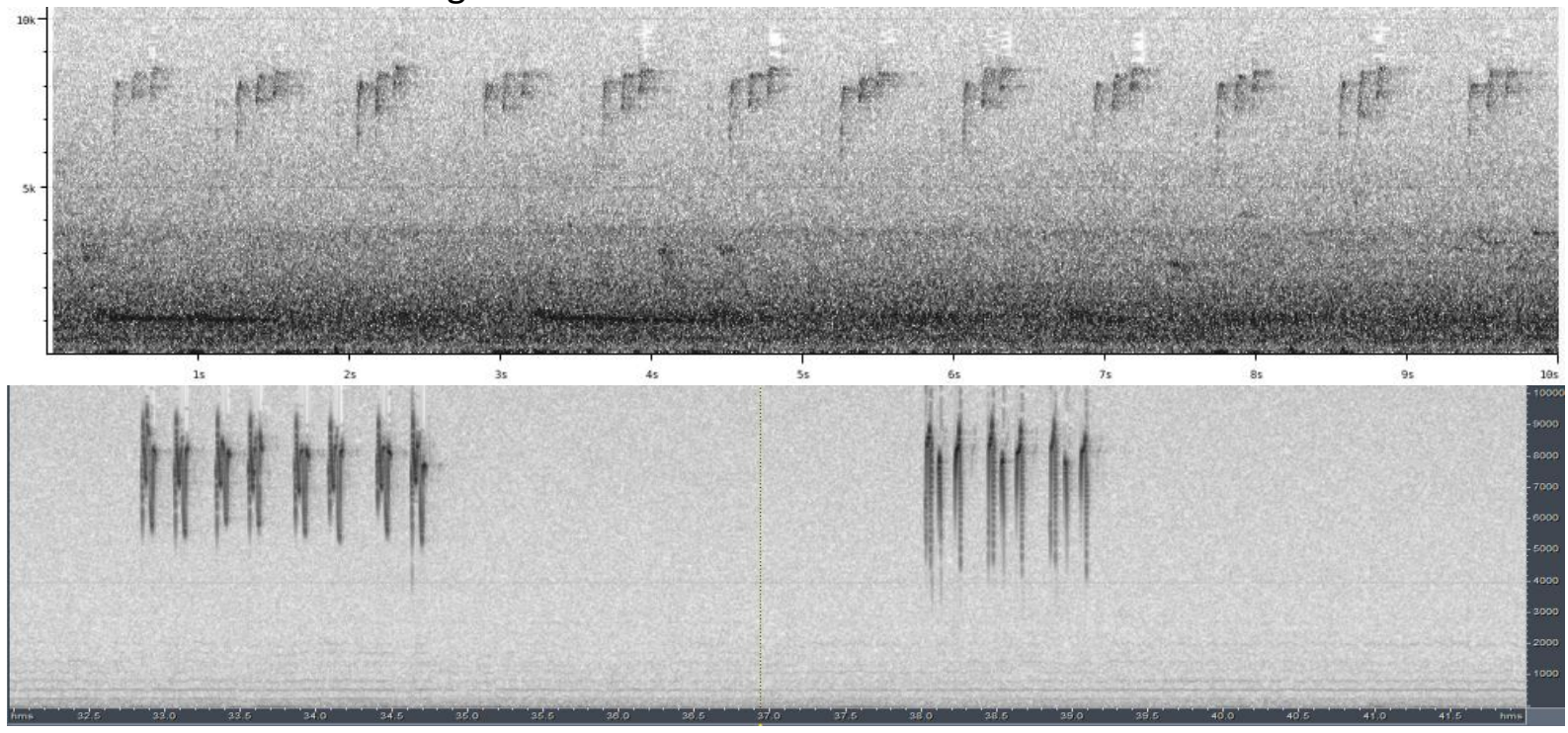

cambodianum: Vocalisations somewhat different from ignipectis/formosum, but birds in SE Thailand also somewhat different from Cambodia. Nevertheless, all seem to lack the higherpitched alternating song of ignipectis/formosum.

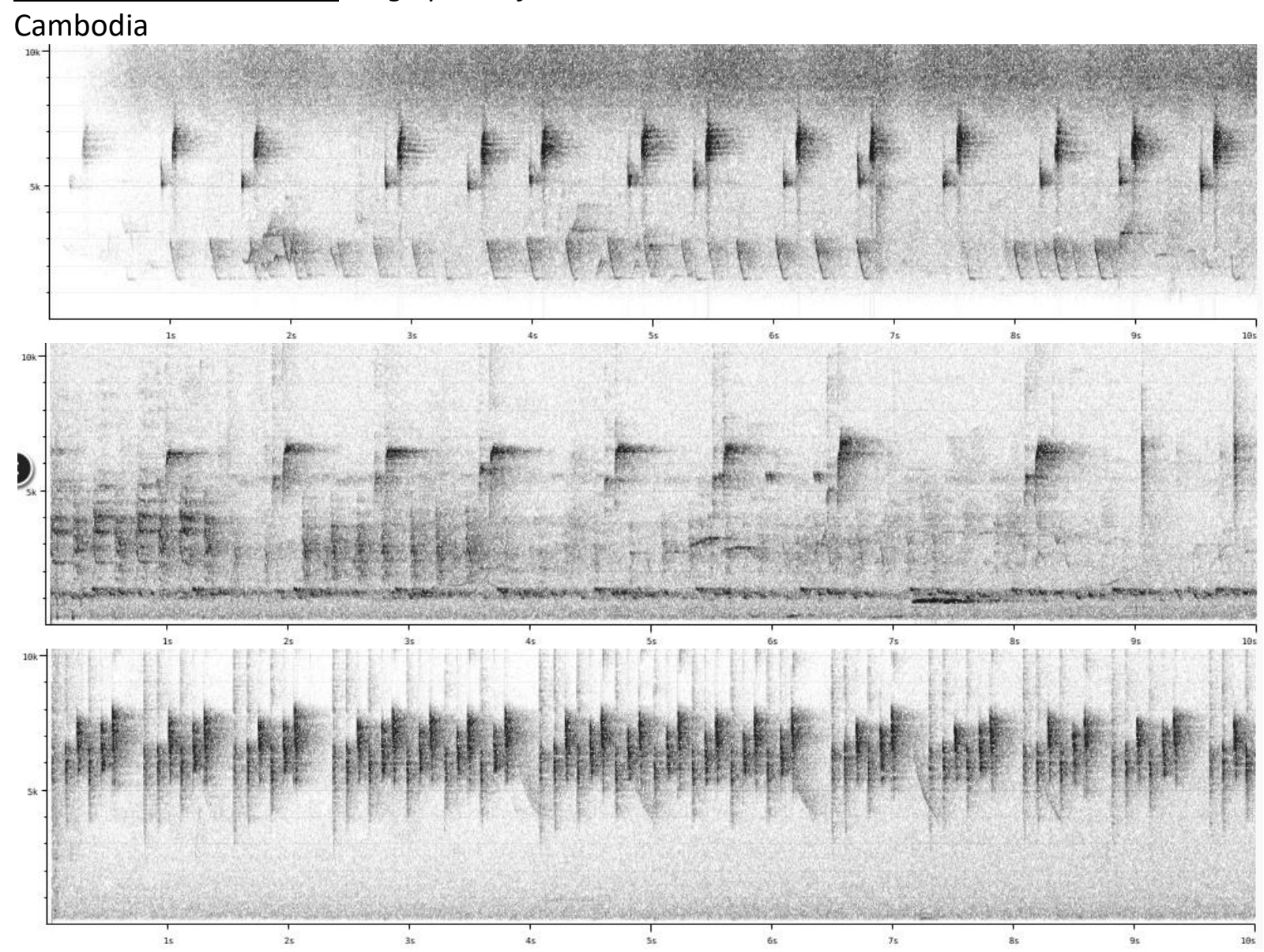




\section{HANDBOOK OF THE \\ BIRDS PF/THE WORLD}

\section{ORNITHOLOGICAL NOTES}

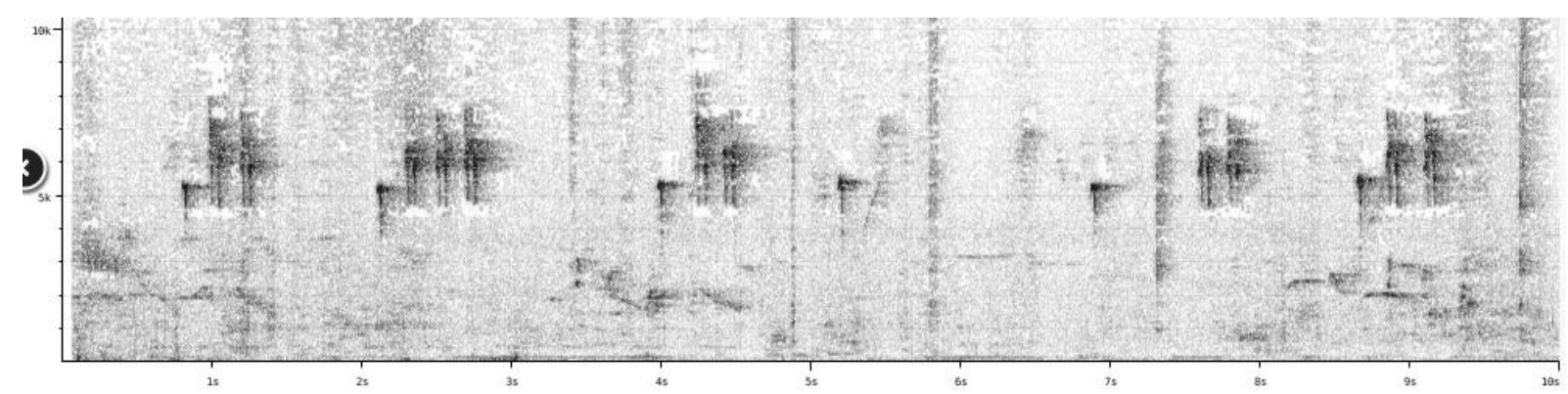

SE Thailand (Khao Yai) Correct subspecies??
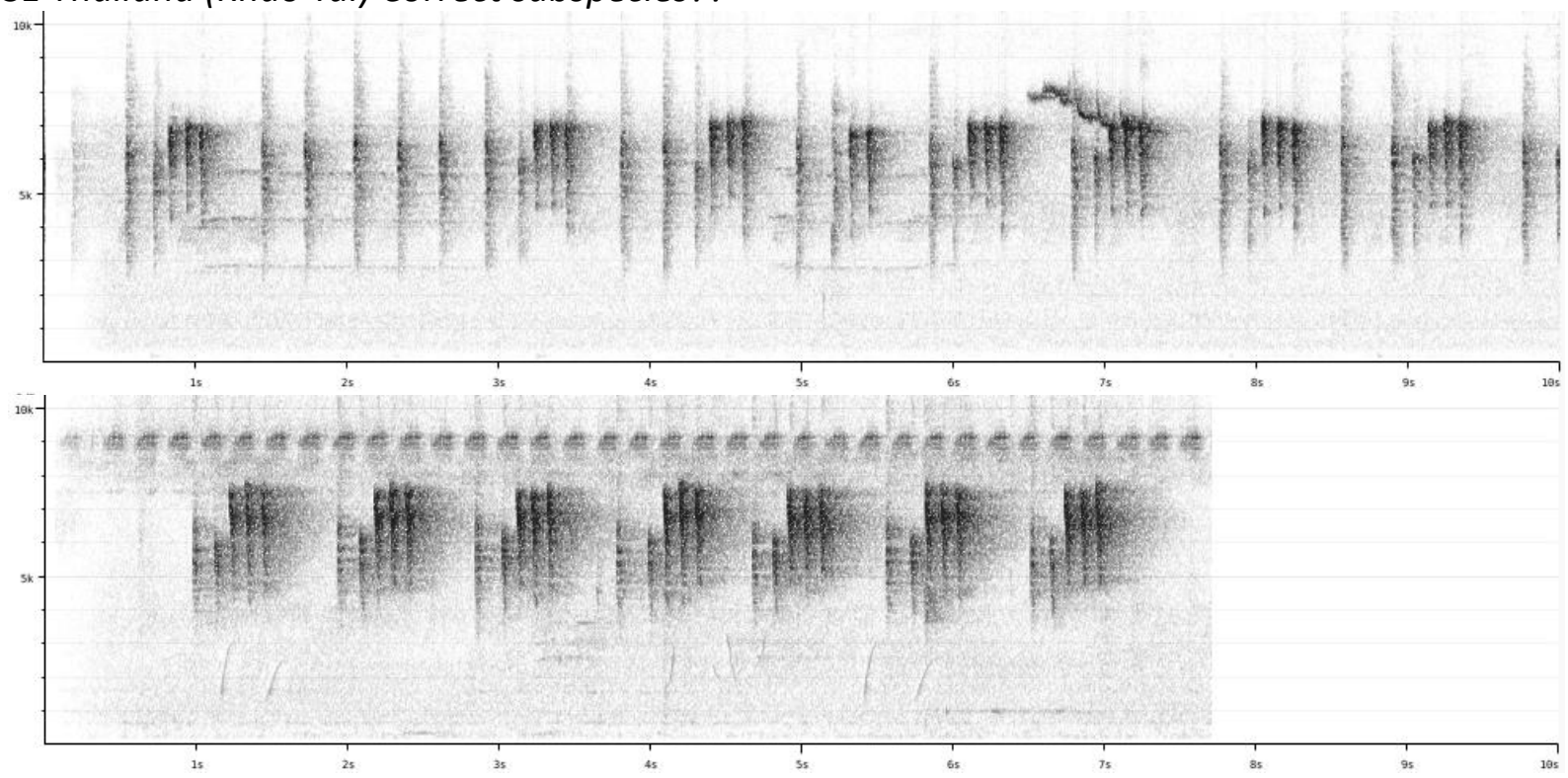

dolichorhynchum: apparently 2 song types: a series of short high-pitched notes rising in pitch, and a series of 2 alternating notes. Voice thus much like ignipectis/formosum.

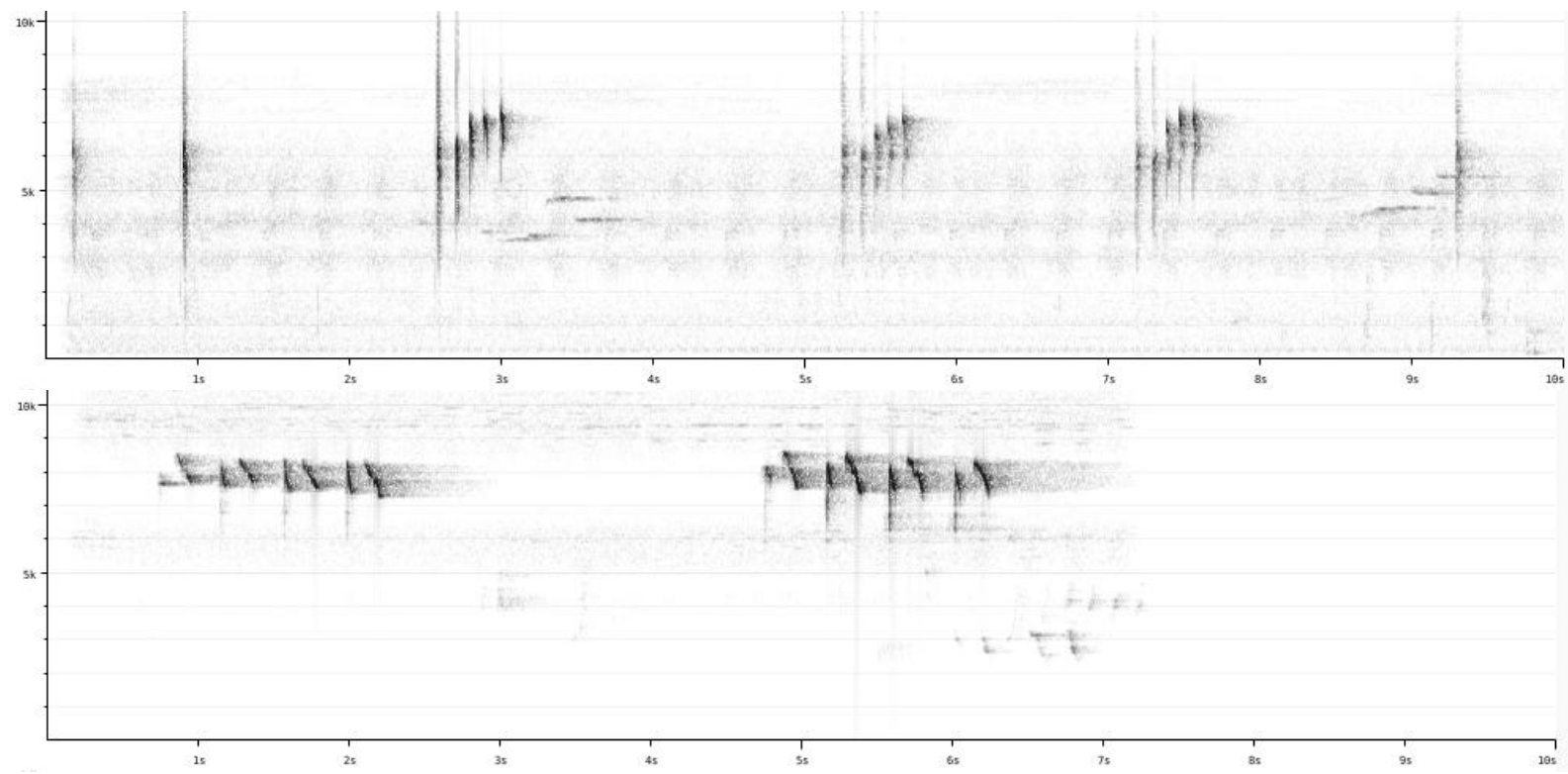




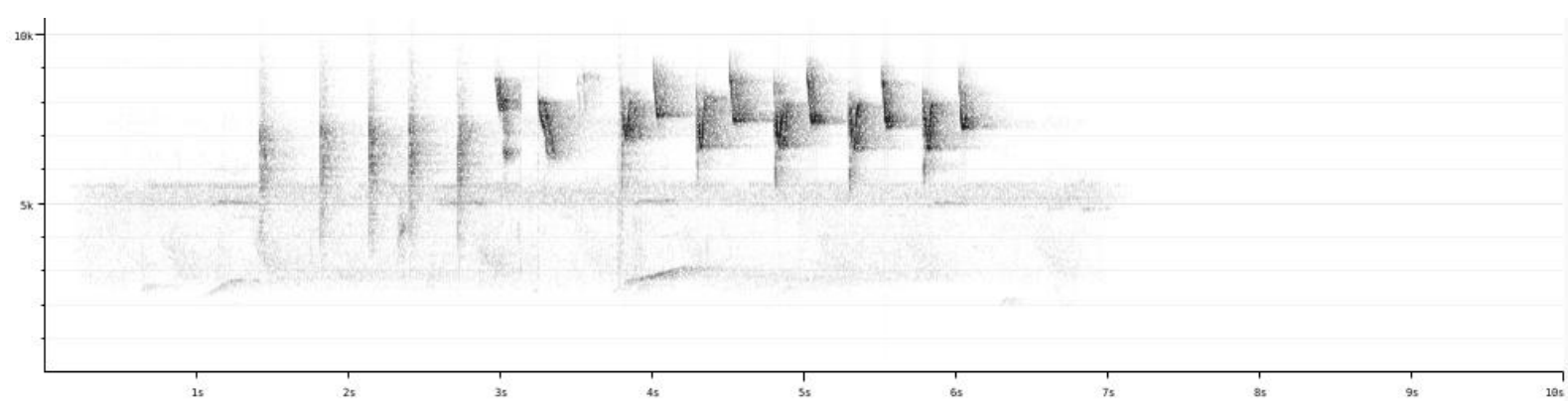

beccarii: Only a single recording available of presumed song. Suggests a different song from above races.

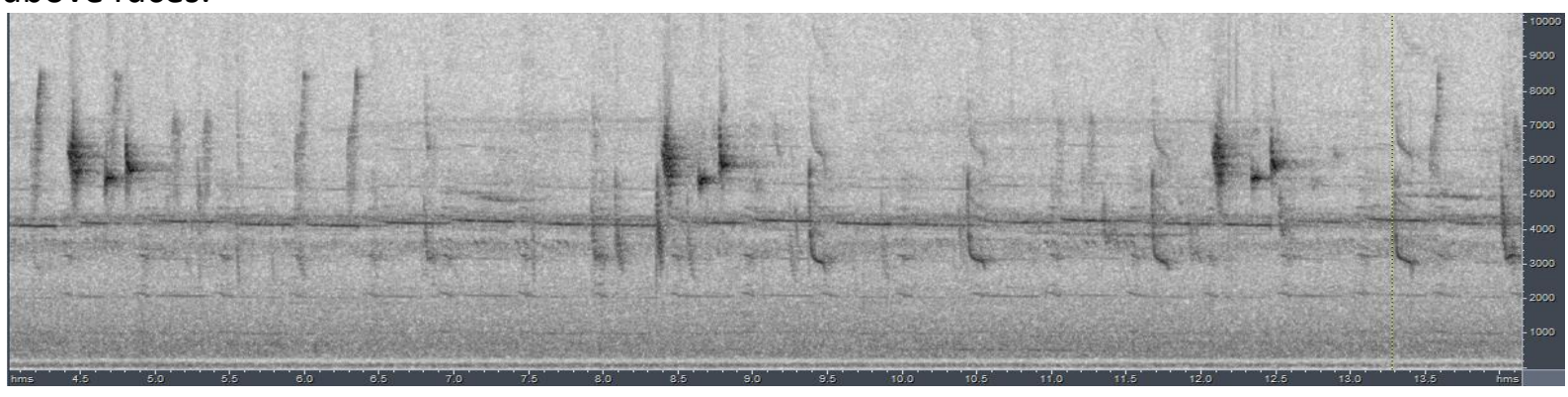

apo: Song a combination of 1-2 intro notes usually followed by a series of (2-9) identical high-pitched notes.

Mindanao (Philippines)

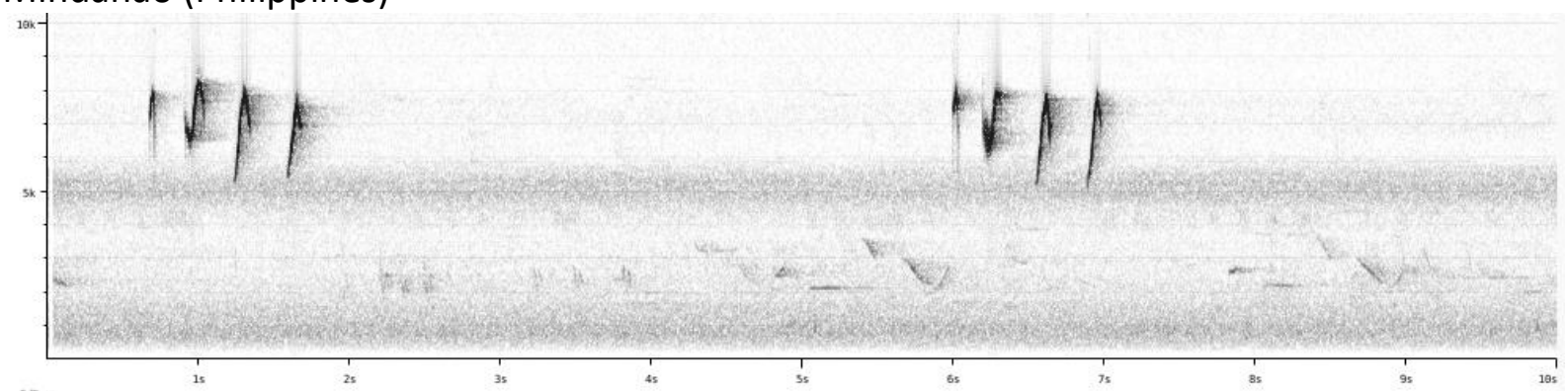

Negros (Philippines)
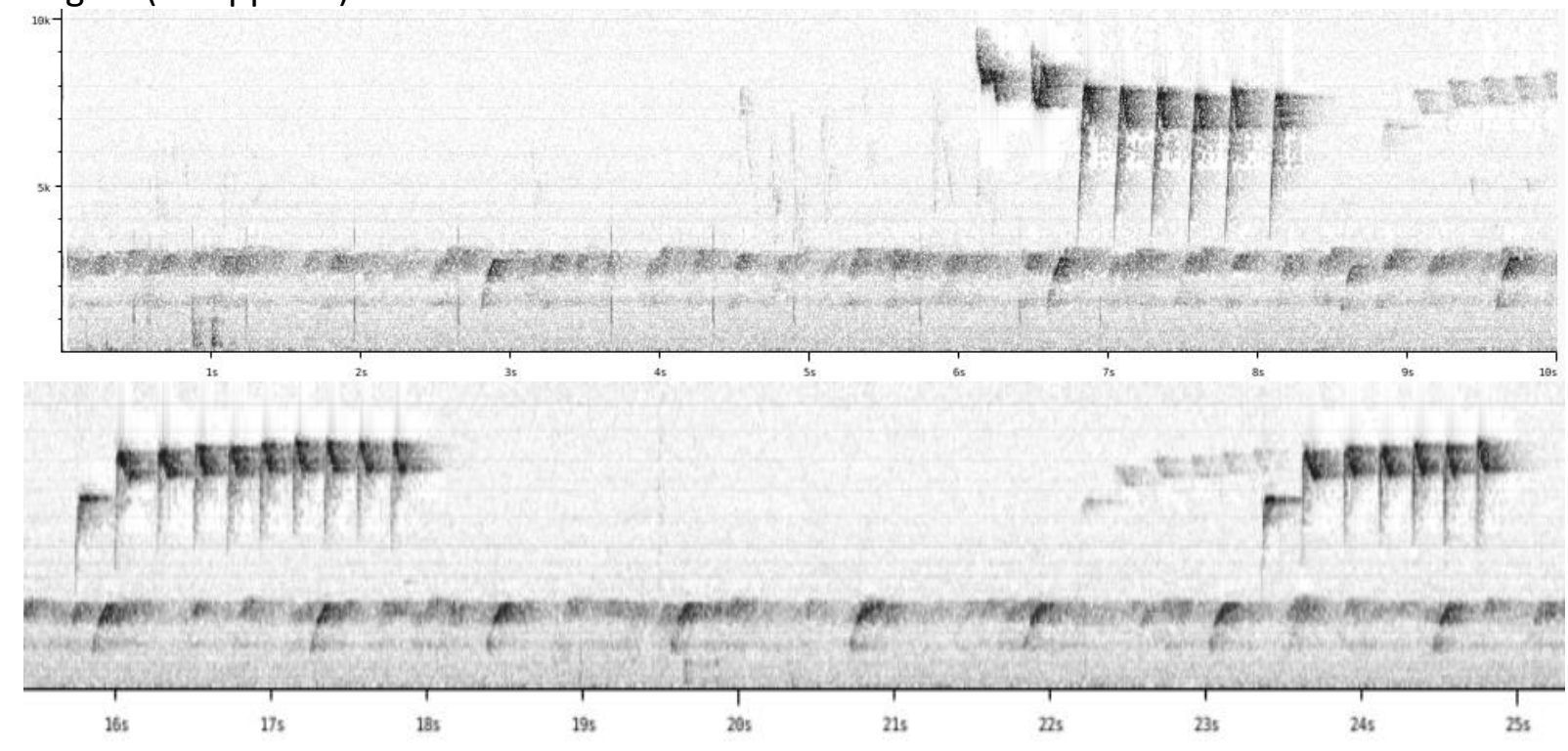

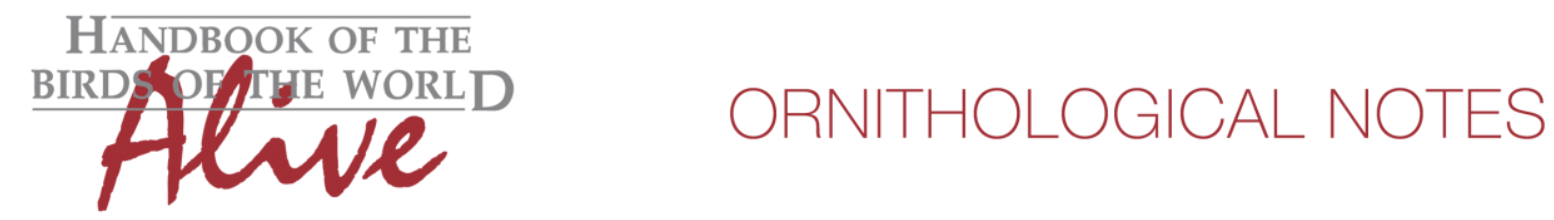

luzoniense: Song a combination of 1-2 intro notes followed by one or more identical highpitched notes (as in apo, but possibly less repeats)
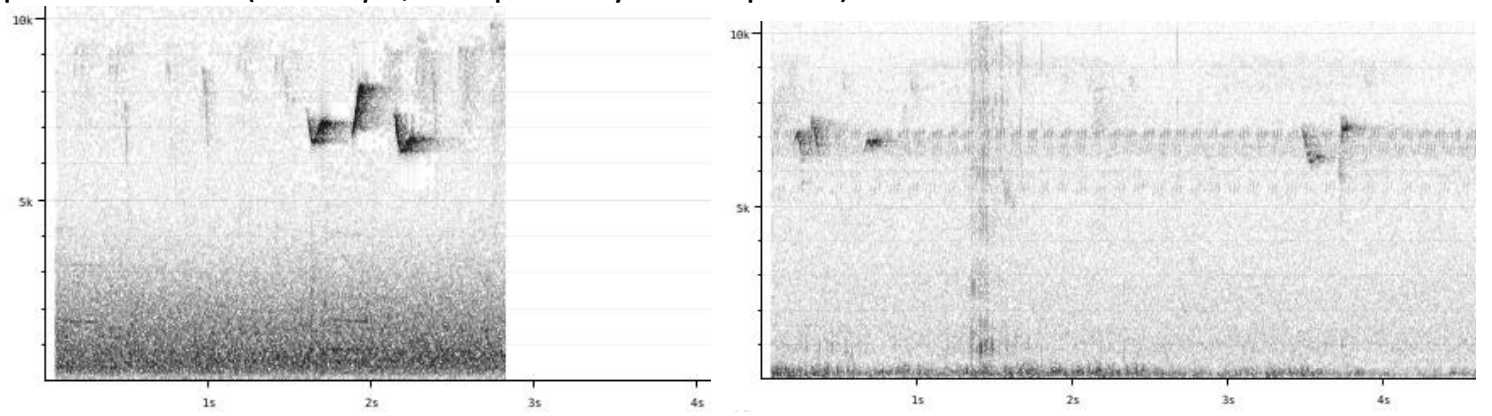

There are thus clearly several vocal groups.

Group 1: ignipectis/formusum/dolichorhynchum. Two song types: a series of short highpitched notes rising in pitch, and a series of 2 alternating notes.

Group 2: cambodianum. Song is a series of short high-pitched notes rising in pitch. Seems to lack the higher-pitched alternating song of ignipectis/formosum. (this could be quantified by e.g. max. freq. which reaches $8-10 \mathrm{kHz}$ in high-pitched alternating song, while vocalisations of cambodianum stay below $8 \mathrm{kHz}->$ score 2-3).

Group 3: beccari. The single available recording suggests a different song. More recordings needed however.

Group 4: Philippine races apo and luzoniense. Song is a combination of 1-2 intro notes usually followed (in some cases) by a series of identical high-pitched notes. Seemingly lacks both the rising series of short staccato notes, and the song of alternating high-pitched notes of mainland races. More recordings needed to determine range of variation, but at this point already clearly different from the mainland races. (If needed to be scored, a tentative score of about 3 could be given, based e.g. on slower pace (1-2), presumed lack of staccato rising note series (1) and lack of alternating notes in high-pitched song (1) of Philippine vocalisations).

As a final remark, it would seem that voice of the Philippine races is actually closer to the song of D. celebicum:

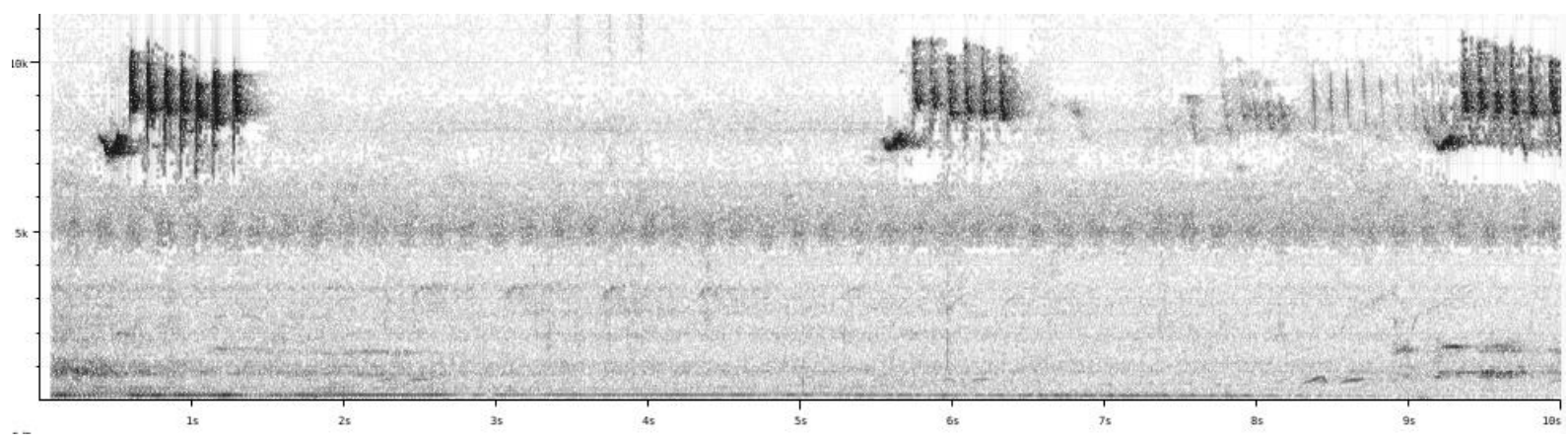



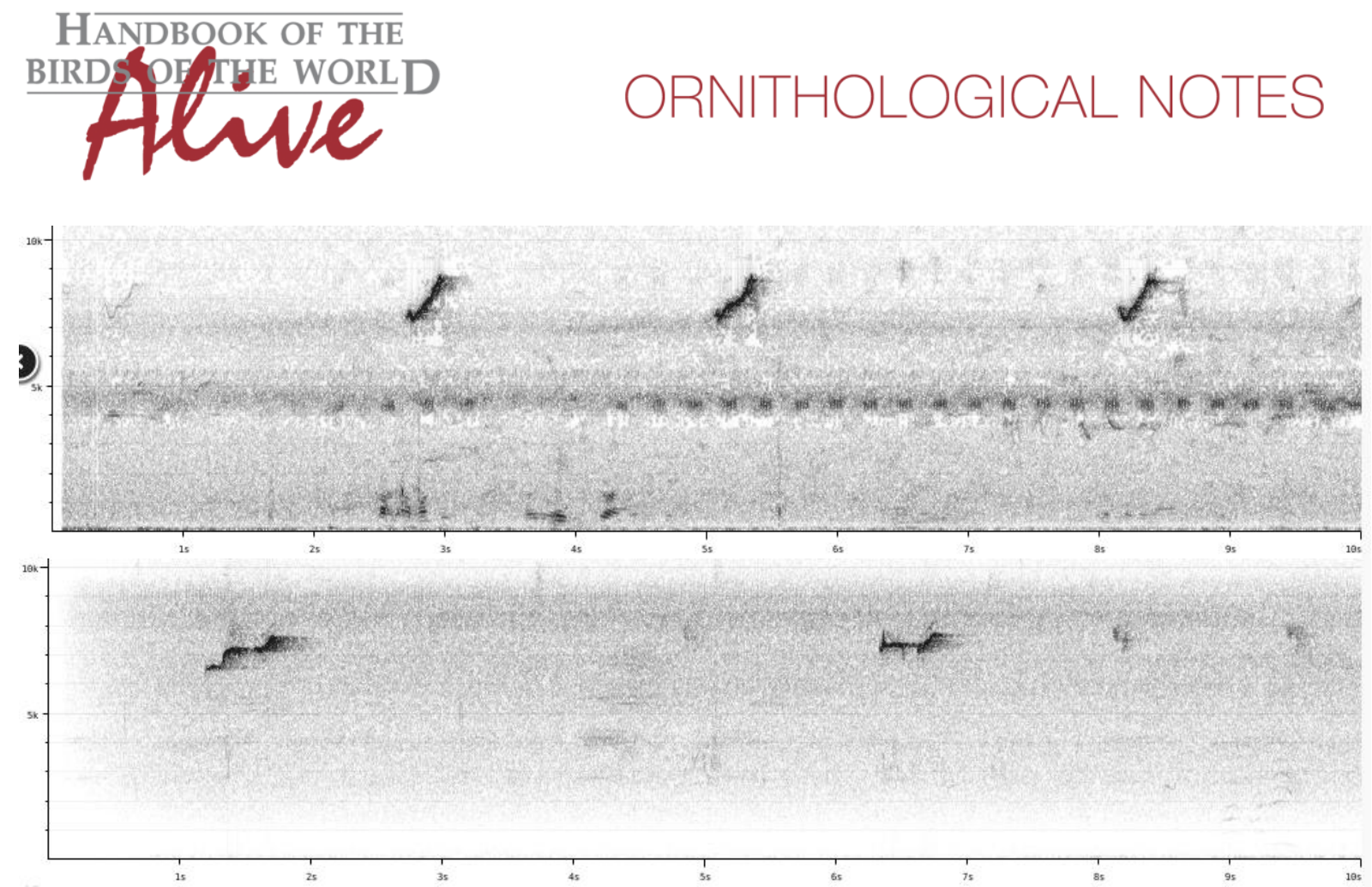

Song seemingly 1-2 high-pitched notes, occasionally followed by a series of high-pitched identical notes. Thus, shows indeed some similarities with apo and luzoniensis, but highpitched notes somewhat longer (allow 2) and flatter-pitched (allow 1).

This note was finalized on 26th July 2016, using sound recordings available on-line at that moment. We would like to thank in particular the many sound recordists who placed their recordings for this species on $\mathrm{XC}$ and $\mathrm{ML}$.

\section{References}

Tobias, J.A., Seddon, N., Spottiswoode, C.N., Pilgrim, J.D., Fishpool, L.D.C. \& Collar, N.J. (2010). Quantitative criteria for species delimitation. Ibis 152(4): 724-746.

\section{Recommended citation}

Boesman, P. (2016). Notes on the vocalizations of Fire-breasted Flowerpecker (Dicaeum ignipectus). HBW Alive Ornithological Note 409. In: Handbook of the Birds of the World Alive. Lynx Edicions, Barcelona. (retrieved from http://www.hbw.com/node/1253805 on 4 December 2016). 